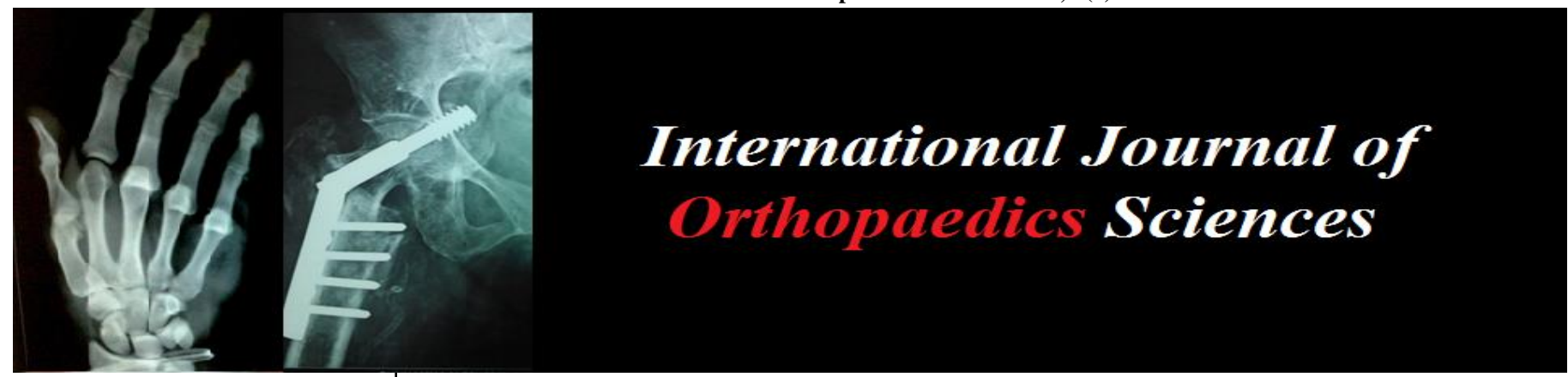

E-ISSN: 2395-1958

P-ISSN: 2706-6630

IJOS 2019; 5(4): 192-195

(C) 2019 IJOS

www.orthopaper.com

Received: 16-08-2019

Accepted: 20-09-2019

Tanveer Ahmed Bhat Senior Resident, Orthopaedics, SGGRIM \& HS, Dehradun, Uttarakhand, India

Mohammad Farooq Butt

Assistant Professor,

Orthopaedics, GMC, Jammu,

Jammu and Kashmir, India

Imtiyaz Ahmad Beigh Senior Resident, Orthopaedics, SGGRIM \& HS, Dehradun,

Uttarakhand, India

Sayar Ahmad Mantoo Senior Resident, Orthopaedics, SGGRIM \& HS, Dehradun, Uttarakhand, India

Malik Naseer Ahmad Medical Officer, Department of Health, Jammu and Kashmir, India

Irhad Ahmad Ganie Senior Resident, Orthopaedics, SGGRIM \& HS, Dehradun,

Uttarakhand, India
Corresponding Author: Imtiyaz Ahmad Beigh Senior Resident, Orthopaedics, SGGRIM \& HS, Dehradun, Uttarakhand, India

\section{Comparative study of intramedullary nailing in reverse obliquity intertrochanteric fractures with or without Cerclage wire augmentation}

\author{
Tanveer Ahmed Bhat, Mohammad Farooq Butt, Imtiyaz Ahmad Beigh, \\ Sayar Ahmad Mantoo, Malik Naseer Ahmad and Irhad Ahmad Ganie
}

DOI: https://doi.org/10.22271/ortho.2019.v5.i4d.1672

\section{Abstract}

Background: Reverse obliquity intertrochanteric fracture is a challenging injury encountered by orthopaedic surgeons. The patients are usually osteoporotic, with multiple co-morbidities and poor tolerance for complications and re-operations. In such a difficult scenario an intramedullary nail is recommended to give a stable fixation. This study aims to compare results between fracture fixation by only intramedullary nailing and nailing with augmentation by cerclage wires.

Material and Methods: This prospective study includes 53 patients from August 2016 to September 2018 that presented to our institute with a reverse obliquity intertrochanteric fracture. They were sequentially operated with either intramedullary nailing (IMN) or nailing with additional use of cerclage wires. Patients were followed up for a minimum of 12 months. Radiological union time, complications and functional outcome (using Harris Hip Score) were noted at 1 year. Statistical analysis was performed to compare the results in both groups.

Results: The mean union time was $4.3 \pm 0.534$ months in Group A and $3.8 \pm 0.534$ months in group B. The mean operating time needed for cerclage-augmentation was 10 minutes more than IMN only. The incidence of complications like screw cut out, back out and non-union, re-operation rate was lower in cerclage group. But the incidence of deep infection at the fracture site was more in cerclage group. Cerclage group had good functional outcome which was statistically significant.

Conclusions: The technique of using cerclage wires in addition to intramedullary nail in reverse obliquity intertrochanteric fractures for lateral wall reconstruction provides good radiological and functional outcomes. It also reduces many complications of the procedure. Only concerning factor remains the increased risk of infection at the fracture site.

Keywords: Comparative, intramedullary nailing, reverse obliquity

\section{Introduction}

Reverse obliquity fracture, a term coined by Wright, is different from other intertrochanteric fractures in that the major fracture line runs from distal-lateral to proximal-medial at or just below the lesser trochanter. According to classification systems it is Boyd and Griffin type 3, Evan's type 2 and OTA type 31A3.1. Muscles acting on the proximal femur result in a flexed, abducted, and externally rotated proximal fragment, and a shortened and adducted distal fragment, thus resisting the anatomical reduction of the fracture.

The treatment goal is to achieve a stable internal fixation after anatomical reduction, to help patients regain function without pain or limp. Intramedullary nails (IMN) have now been accepted as the best modality of treatment for very unstable trochanteric fractures like reverse obliquity type to achieve stable fixation. IMNs are load sharing implants with smaller bending moments and thus, prevent excessive collapse. Reduction in reverse obliquity type is challenging. Ball-spiked pushers, Schanz pins, reduction clamps and intramedullary reduction tools have been used to facilitate reduction.

In this study we have consistently used large reduction clamps using mini incisions around the fracture site to close the fracture gap. We used stainless steel cerclage wires in one group of patients to augment the fixation of the IMN and compared the radiological and functional outcomes with the cases in which IMN alone was used. 


\section{Material and Methods}

A total of 1870 patients presented to our institute from August 2016 to September 2018 with intertrochanteric fractures. Fractures were classified according to Boyd and Griffin classification system. There were 680 type 1,843 type 2,110 type 3 and 237 type 4 fractures. We used following criteria to form our study group.

\section{The Inclusion criteria}

Age> 50 years

Independent ambulation prior to injury

Boyd Griffin type 3/ Evan's type 2/ OTA type 31A3.1

\section{Exclusion criteria}

Non-ambulatory prior to injury

Previous ipsilateral femoral/ hip surgery

Segmental fractures

Bilateral fractures

Pathological fractures

\section{Compound fractures}

Only ninety-five out of the 110 patients with reverse obliquity intertrochanteric fractures fulfilled the above criteria. Five patients refused surgery. Ninety patients underwent surgical procedure within 5 days of the injury. 54 cases were males and 36 were females. The mean age of patients was 62.3 years.

\section{Surgical Technique}

After proper anaesthesia, patients were placed in supine position on the traction table. The unaffected extremity was placed in hemilithotomy position while the fractured extremity was mounted on traction boot. Femoral shaft was lifted to reduce posterior sag. Next traction was applied. For reducing posterior translation extremity was flexed (30-40 degrees) with knee in extension. Leg was rotated to align with proximal fragment. The reduction was checked with AP and lateral c-arm images. In 30 cases, closed reduction was achieved and standard antegrade nailing was performed without any need of additional reduction techniques. These cases were excluded from the final comparative analysis as these didn't require open procedure. We used either the standard proximal femoral nail antirotation or the long proximal femoral nail antirotation (PFNA; Synthes). In case it was difficult to achieve closed reduction, open reduction using a mini-incision at the fracture site was done. Large reduction clamps were placed from medial to lateral to close the fracture gap. After satisfactory reduction a guide-wire was passed just medial to the tip of greater trochanter. A nail with diameter 1 to $2 \mathrm{~mm}$ less than the largest size reamer used was inserted by the usual technique. Clamp was held in place during reaming and subsequent passage of nail and was removed only after cephalomedullary lag screw and distal screws were placed. This was type of fixation could be achieved in 40 patients (Group A).

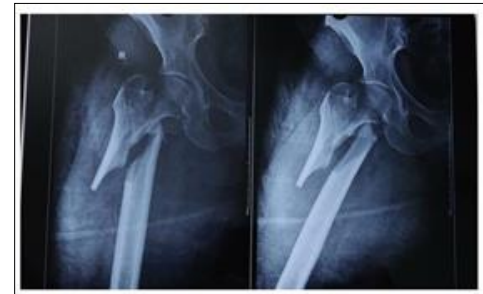

A

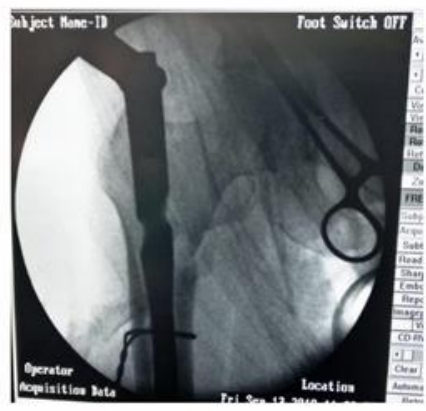

E

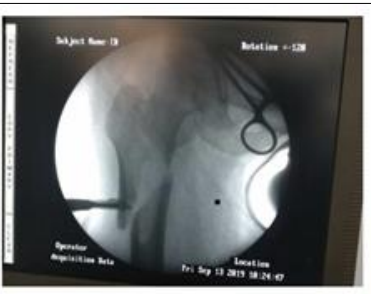

B

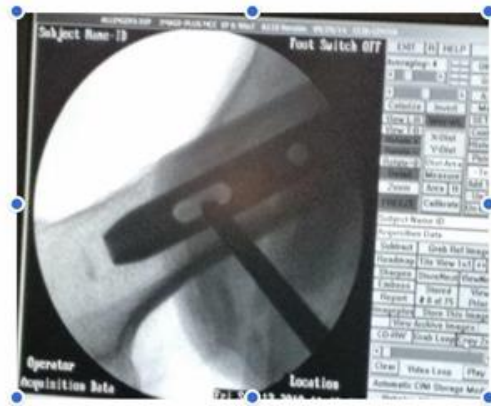

$\mathrm{F}$

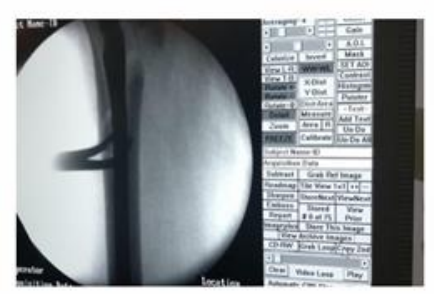

C

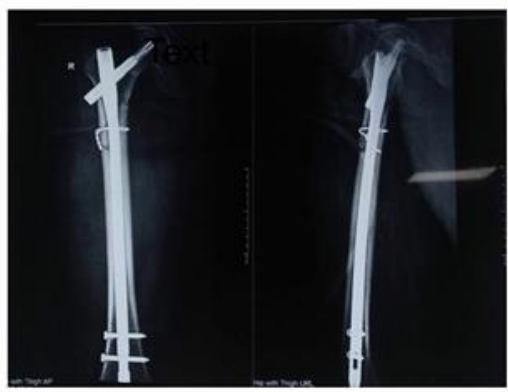

G

Fig 1: Pre-op radiograph of a reverse obliquity intertrochanteric fracture (A),intraoperatively fracture site was opened by mini incision as fracture wasn't properly reduced (B), reduction held by bone clamp (C), cerclage wire used to hold reduction (D), nail inserted while fracture is reduced anatomically (E), Distal free hand locking being done (F), post-op radiographs, AP and lateral $(\mathrm{G})$.

Behavior of the fracture was noted fluoroscopically after clamp removal. In case of any fracture displacement a single cerclage wire was placed by an $\mathrm{AO}$ wire passer through the same incision to hold the fracture ends. The excess wire was cut and the Knot Bent and tapped inside the wound. This was followed by nailing in the standard fashion (Fig. 1)

Cerclage-assisted fixation was done in 30 patients (Group B). Common errors that occur with nailing like loss of reduction with nail insertion, lag screw migration, incorrect screw position and fracture propagation were prevented.

Patients were followed up at 1.5 months, 3 months, 6 months and 1 year. At follow-up, functional outcomes were assessed by Harris Hip Score (HHS) and X-rays of the proximal femur in AP and lateral projections were obtained.

Clinical union was defined as a painless fracture site while the patient walked without any aids. Radiographic union was defined as bridging callus in three cortices in two orthogonal X-rays. Nonunion was defined as implant breakage or cutout. Radiodiographic nonunion was defined as no signs of healing at six months postoperatively. The varus-valgus cervical angle was measured, with acceptable range being considered between 125 and 135 degrees. Reduction was judged 
anatomic if displacement was $<4 \mathrm{~mm}$. The blood loss and operating time of each surgery was noted. The post-operative rehabilitation protocol was same for both groups.

\section{Results}

Of the 60 patients included in the comparative analysis, 40 patients were fixed by PFN by clamp-assisted reduction and were included in Group A. 20 patients required additional use of a cerclage wire to hold the reduction. These were included in Group B. Seven patients (four from group A, three from Group B) died with in 1 year of surgery due to medical comorbidities. So only 53 patients were available for the final analysis.

The mean operation time was $45 \pm 4.5$ minutes in group A and $55.2 \pm 4.5$ minutes in group $\mathrm{B}$. The mean blood loss was $50+/-$ $5 \mathrm{ml}$ in group A and $80+/-5 \mathrm{ml}$ in group B. There were no intraoperative deaths. Anatomic fracture reduction $(<4 \mathrm{~mm}$ gap) could be achieved in $58.33 \%$ (21 cases) in group A as compared to $82.35 \%$ (14 cases) in group B (Table 1).

Table 1: Comparison of various operative variables between unaugmented group A and Cerclage-augmented group B.

\begin{tabular}{|c|c|c|}
\hline Operative Variables & Group A & Group B \\
\hline Operative time & $45+/-4.5 \mathrm{mins}$ & $55.2+/-4.5 \mathrm{mins}$ \\
\hline Blood loss & $50+/-5 \mathrm{ml}$ & $80 \mathrm{ml}+/-5 \mathrm{ml}$ \\
\hline Fracture Reduction & & \\
\hline$<4 \mathrm{~mm}$ gap & $21(58.33 \%)$ & $14(82.35 \%)$ \\
\hline$>4 \mathrm{~mm}$ gap & $15(41.66 \%)$ & $3(17.64 \%)$ \\
\hline
\end{tabular}

There were no deaths in the immediate post-op period. Two patients from group A and four from group B developed deep venous thrombosis in the post-op period which resolved over a course of 2 to 3 Weeks. Two patients in group A and five from group B developed surgical site infection. While in Group A, infection at nail entry site settled after few days, patients from group B had deep infection at the fracture site wound. All five required wound wash and extended antibiotic therapy. Vacuum assisted closure was required in two of these cases.

In the non-augmented group (group A), 3 cases had screw penetration into hip joint. In group B, screw penetration was seen in one patient. All the four cases required revision surgery. In group A, 5 patients had screw backing-out of the proximal femur but were clinically asymptomatic and did not require revision surgery at 1 year follow-up. In group B no patient had such a complication. In group A, 2 patients had non-union. One patient was re-operated and total hip arthroplasty was done. The other refused re-operation. In group B no non-union was seen. In group A, varus angulation was seen In 5 patients, with no clinical symptoms. In group B, varus was noted in 1 patient with mild pain in the hip joint (Table 2).

Table 2: Comparison of various complications between unaugmented (Group A) and cerclage-augmented (Group B)

\begin{tabular}{|c|c|c|}
\hline Complications & Group A & Group B \\
\hline Superficial SSI & 2 & 4 \\
\hline Deep SSI & 1 & 4 \\
\hline Non-union & 2 & None \\
\hline VAC requirement & None & 2 \\
\hline Screw penetration & 3 & 1 \\
\hline Screw backout & 5 & None \\
\hline Varus angulation & 5 & 1 \\
\hline Need for revision surgery & 4 & 2 \\
\hline
\end{tabular}

The mean union time in group A was $4.3 \pm 0.534$ months while that in group B was $3.8 \pm 0.534$ months. The result was analysed using the Chi-square test. The result is statistically significant at $p<0.05(0.0041)$.

Harris hip scores at final follow-up were better in group B with excellent score in $35.29 \%$ cases in group B as compared to $27.77 \%$ cases in group A (Table 3 ). The Chi-square test was used to analyse the results and was found to be significant at $p<0.05(0.030)$

Table 3: Comparison of functional outcome between un-augmented group A and cerclage-augmented group B.

\begin{tabular}{|c|c|c|}
\hline Harris Hip Score & Group A & Group B \\
\hline$<70$ Poor & $2(5.55 \%)$ & $1(5.88 \%)$ \\
\hline $70-79$ Fair & $6(16.66 \%)$ & $1(5.88 \%)$ \\
\hline $80-89$ Good & $18(50.0 \%)$ & $9(52.94 \%)$ \\
\hline 90-100 Excellent & $10(27.77 \%)$ & $6(35.29 \%)$ \\
\hline Total & 36 & 17 \\
\hline
\end{tabular}

\section{Discussion}

Being biomechanicaly different from other intertrochanteric fractures, reverse obliquity type fractures pose a challenge while reduction. A. Afsari et al. in a series of forty-four subtrochanteric fractures concluded that clamp-assisted reduction and intramedullary nail fixation techniques with judicious use of a cerclage cable can result in excellent reductions and a high union rate ${ }^{[1]}$. S.G. Kulkarni et al. in a series of 154 unstable intertrochanteric fractures concluded that the technique of augmentation of fixation of intramedullary nail using cerclage wires and lag screws is useful in reducing complications of the procedure ${ }^{[2]}$. $\mathrm{T}$. Apivatthakakul and C. Phornphutkul suggested that percutaneous wiring is an alternative reduction technique to facilitate the reduction and maintenance of difficult femoral fractures ${ }^{[3]}$. Kilinc et al. Suggested that open reduction and the use of cerclage did not produce a negative effect in terms of fracture union ${ }^{[4]}$.

The complications of IMN have been well documented [5]. G.J. Haidukewych et al. in a series of 1035 intertrochanteric and subtrochanteric fractures suggested that the results were worse for fractures with poor reduction and those with a poorly placed implant ${ }^{[6]}$.

The lag screw tip protruding in the hip joint causes arthritic changes of the hip joint. Uzun et al. report a re-operation rate of $14 \%$ due to many complications, mostly for exchange of the penetrated screw ${ }^{[7]}$. Comparative studies in different types of IMN methods have shown that fracture impaction and collapse are important factors in causing screw cut-out ${ }^{[8]}$. Fogagnolo et al. have demonstrated a cut out rate of $10 \%$ in their study, emphasizing the need for anatomical reduction of the fracture ${ }^{[9]}$.

Medialization of shaft, varus collapse and lateral wall instability are frequently encountered complications in intertrochanteric fractures ${ }^{[10,11]}$. Intramedullary nails give much better stability as compared to the dynamic hip screw leading to decreased incidence of collapse into varus ${ }^{[12]}$.

Screw cut-out rate in our study was $13.88 \%$ in patients treated with IMN only, and no cut- out was observed in patients in whom lateral wall reconstruction using cerclage wire was done. The difference in outcome is statistically significant.

Re-operation rates have been reported to be as high as $19 \%$ in some studies ${ }^{[9]}$. Re-operation required usually is an arthroplasty, which is challenging to both the surgeon as well as the patient ${ }^{[13]}$. Patients in group A required more revision 
surgeries (11.11\%). On the other hand, only one case $(5.88 \%)$ in group B patients required conversion to arthroplasty.

The difference in mean union time $(4.3 \pm 0.534$ months in group A versus $3.8 \pm 0.534$ months in group B) was statistically significant. There was one case of non-union in group A, who required a total hip arthroplasty. There was no non-union in group B. Five cases of varus malunion were seen in group A and only one case in group B.

Although there remains a concern of increased risk of deep infection it can be concluded that cerclage wire augmentation of intramedullary nailing leads to lesser incidence of varus collapse and non-union as well as better functional outcomes.

\section{Conclusion}

The use of cerclage wires as augmentation to the intramedullary nail provides better stability to the lateral and posteromedial wall. This reduces complications like screw cut-out and fracture collapse. The functional outcome is better due to increased stability and better union rates.

Note: This study was conducted during the residency of corresponding author at Government Medical College, Jammu.

\section{References}

1. Alan Afsari, Frank Liporace, Eric Lindvall, Anthony Infante Ir., Henry C. Sagi, and George J. Haidukewych. Clamp-Assisted Reduction of High Subtrochanteric Fractures of the Femur. Jboneioint Surg Am. 2009; 91:1913-8. • dol:10.2106/JBJS.H.01563

2. Sunil Govind Kulkarnia, Sushrut Sudhir Babhulkarb, Sujay Milind Kulkarnia, Govind Shivram Kulkarnia, Madhura Sujay Kulkarnia, Raviraj Patila. Augmentation of Intramedullary Nailing in unstable intertrochanteric fractures using cerclage wire and lag screws: A comparative study. Injury, Int. J Care Injured 48S2, 2017, S18-S22.

3. Apivatthakakul T, Phornphutkul C. Percutaneous cerclage wiring for reduction of periprostheticand difficult femoral fractures. A technical note Injury, Int. J Care Injured. 2012; 43:966-971

4. Kilinc BE, Oc Y, Kara A, Erturer RE, The Effect of The Cerclage Wire In The Treatment of Subtrochanteric Femur Fracture With The Long Proximal Femoral Nail: A Review of 52 Cases, International Journal of Surgery, 2018, DOI: 10.1016/j.ijsu.2018.06.035.

5. Erez O, Dougherty PJ. Early complications associated with cephalomedullary nail for intertrochanteric hip fractures. J Trauma Acute Care Surg. 2012;72(2):E1015 .

6. Haidukewych GJ, Berry DJ, Nonunion of fractures of the Subtrochanteric Regionofthe Femur. Clin Orthop Relat Res. 2004; 419:185-8.

7. Uzun M, Erturer E, Ozturk I, Akman S, Seckin F, Ozcelik IB. Long-term radio-graphic complications following treatment of Unstable Intertrochanteric Femoral fractures with the proximal Femoral Nail and effects on functional results. Acta Orthop Traumatol Turc. 2009; 43(6):457-63.

8. Schipper IB, Steyerberg EW, Castelein RM, van der Heijden FH, den Hoed PT, Kerver AJ et al. Treatment of unstable trochanteric fractures. Randomised com- parison of the gamma nail and the proximal femoral nail. J Bone Joint Surg Br. 2004; 86(1):86-94.

9. Fogagnolo F, Kfuri M, Paccola CAJ. Intramedullary fixation of pertrochanteric hip fractures with the short AO-ASIF proximal Femoral Nail. Arch Orthop Trauma Surg. 2004; 124(1):31-7.

10. Gotfried Y. Integrity of the lateral femoral wall in intertrochanteric hip fractures: An important predictor of a reoperation. J Bone Joint Surg Am. Author Reply 2553. 2007;89(11):2552-3.

11. Huang H, Xin J, Ma B. Analysis of complications of intertrochanteric fracture treated with Gamma 3 Intramedullary Nail. Int. J Clin Exp Med. 2014; 7(10):3687-93.

12. Klinger HM, Baums MH, Eckert M, Neugebauer R. A comparative study of unsta- ble per- and intertrochanteric femoral fractures treated with dynamic hip screw (DHS) and Trochanteric Butt-Press plate vs. proximal femoral nail (PFN). Zentralbl Chir. 2005;130(4):301-6.

13. Pachore JA, Shah VI, Sheth AN, Shah KP, Marothi DP, Puri R. Hip arthroplasty in failed intertrochanteric fractures in elderly. Indian J Orthop. 2013; 47(6):572-7. 